\title{
Os "Hidronegócios" nos rios da Amazônia
}

The "Hydrobusinesses" in the Rivers of the Amazon

\author{
Iane Maria da Silva Batista* \\ Leila Mourão Miranda**
}

\section{RESUMo}

$\mathrm{O}$ artigo discute a história dos rios amazônicos como lugares de "hidronegócios", analisando as fontes e a produção historiográfica sobre os registros de usos e representações das águas, bem como os processos de apropriação dos rios no contexto do planejamento do desenvolvimento regional entre 1950 e 1985, norteado pelas ideias de progresso e crescimento econômico. As fontes utilizadas, discursos, legislações, planos e relatórios de governo e o diálogo com bibliografias clássicas e contemporâneas sobre diversos aspectos das interações entre rios e sociedades humanas demonstram que os rios amazônicos desempenharam papel central na ocupação do território, na circulação de pessoas, ideias e mercadorias e na subsunção da água como força motriz de operações industriais e urbanas, em especial dos grandes projetos mínero-metalúrgicos. As águas foram ressignificadas em quilowatts e commodities, secundarizando as relações mantidas pelas comunidades com os rios.

Palavras-chave: hidronegócios; Amazônia; rios.

\begin{abstract}
This paper focuses on Amazon rivers history as "hydrobusiness" systems. It is based on sources of historiographical production from recordings of water use and representations using analysis of river appropriation, in the context of regional development planning between 1950 and 1985, which emphasized progress and economic growth. The sources used were speeches, legislation, government plans and reports, and dialogue with classic and contemporaneous bibliography concerning the various aspects of interactions between rivers and human societies. The sources showed that Amazon rivers have played a central role in territory occupation, circulation of people, ideas, merchandise and subsumption of water as a propelling force for industrial and urban operation, notably large mining and metallurgical projects. New meanings have been assigned to the waters: kilowatts and commodities, relegating to an inferior condition the traditional relations between the Amazon and its communities.

Keywords: hydrobusinesses; Amazon; rivers.
\end{abstract}

\footnotetext{
* Universidade Federal do Pará (UFPA), Faculdade de Arquivologia, Instituto de Ciências Sociais e Aplicadas, Belém, PA, Brasil. iane@ufpa.br <https://orcid.org/0000-0001-5940-2408>

** Universidade Federal do Pará (UFPA), Programa de Pós-Graduação em História Social da Amazônia, Belém, PA, Brasil. miranda.mourao@bol.com.br <https://orcid.org/0000-0002-5273-1900>
} 
A história dos rios amazônicos como lugares de "negócio", aqui abordada, articula-se à produção historiográfica de registros de usos e representações das águas. Dialoga com as discussões contemporâneas envolvendo setores dos movimentos sociais que sistematizaram a terminologia "hidronegócio" para nomear injunções políticas e econômicas norteadas pela relação mercantil com a água. Compreendem-se hidronegócios como literalmente todos os tipos de negócios envolvendo a água (Malvezzi, 2012), sejam o ramo de água engarrafada, a irrigação da agricultura comercial, a privatização de mananciais de água ou a construção de barragens para produção de energia hidrelétrica, entre outros.

O contexto histórico analisado é o processo de utilização dos rios no âmbito da ideia de progresso e do planejamento do desenvolvimento da Região Amazônica brasileira no século XX. Entre 1900 e 1950 foram implantados projetos pelo governo federal e por grupos empresariais do Centro-Sul do país, articulados ao capital internacional, voltados à recuperação e dinamização de empresas seringalistas e à ocupação da região. Na segunda metade do século instituíram-se e implantaram-se os projetos de desenvolvimento e (re)integração da região à economia nacional e internacional. Esses projetos promoveram a apropriação agropecuária, mineradora, hidrológica e colonizadora dos "recursos da natureza", com apoio fiscal e creditício institucional, alterando as políticas e as bases produtivas e socioculturais da região e na região.

Segundo Ab'Sáber (2003, p. 67-69), os rios são reconhecidos e classificados pela cor das águas, pela ordem de grandeza dos cursos d'água, por sua largura, volume e posição fisiográfica, assim como pelo sentido, continuidade e duplicidade da correnteza. Os rios amazônicos, vias de tráfego de ideias, gente e mercadoria, foram reconfigurados em recurso natural, sem perda daquelas funções, acrescentando-lhes novas formas de negócios: as relacionadas à produção de energia hidrelétrica em escala. Ao reconfigurar os sentidos e significados atribuídos aos rios amazônicos pelas populações regionais, eles foram substantivados como objetos/produtos/mercadorias, redimensionando a cultura de uso dos rios à perspectiva mercantil. Em síntese, suas águas como fonte de energia transformaram-se, também em hidronegócios.

Os planos iniciais de construção de hidrelétricas na Amazônia previam dezenas de grandes e pequenas barragens, considerando o seu potencial para geração de energia, em face do volume de águas circulantes e das quedas topográficas dos afluentes do rio Amazonas. O Plano Nacional de Energia Elétrica 1987-2010 (Brasil, 1987) previa a construção de 68 barragens na Amazônia brasileira, que inundariam 10 milhões de hectares (2\% da região da 
Amazônia Legal e 3\% da porção brasileira de floresta). A dimensão das alterações e perturbações socioambientais seria impactante: alteraria os habitats aquáticos e a vida dos povos indígenas concentrados na maioria dos locais previstos para as construções, em trechos dos rios Xingu, Tocantins, Araguaia e Tapajós, oriundos do planalto central brasileiro (Fearnside, 2015a, p. 13). ${ }^{1}$

O superdimensionamento das águas amazônicas foi o centro do célebre pronunciamento, conhecido como "Discurso do Rio Amazonas", proferido em Manaus em outubro de 1940, pelo presidente Getúlio Vargas: "Nada nos deterá nesta arrancada que é, no século XX, a mais alta tarefa do homem civilizado: conquistar e dominar os vales das grandes torrentes equatoriais, transformando a sua força cega e a sua fertilidade extraordinária em energia disciplinada" (Vargas, 1968, p. 10).

A metáfora do domínio e conquista das "torrentes equatoriais" anunciou as premissas norteadoras do Plano de Valorização Econômica da Amazônia, ${ }^{2}$ que orientou as políticas governamentais na região relativas aos usos dos rios, das terras, florestas e subsolos na segunda metade do século XX. As ideias de selva, barbárie e exuberância da natureza e seus componentes, cunhadas pelos conquistadores e reforçadas por viajantes naturalistas ao longo do século XIX, fundamentaram o discurso de Vargas e foram a matriz de elaboração e aplicação dos planos, programas e projetos a serem executados na região, inclusive em nível educacional. ${ }^{3}$

As águas dos rios amazônicos foram consideradas estratégicas para a ação estatal. No $1^{\circ}$ Plano Quinquenal de Valorização Econômica da Amazônia, executado entre 1955 e 1959, os rios representavam oportunidades para a indústria pesqueira, a navegação e a produção de energia; o 1º Plano Quinquenal de Desenvolvimento da Amazônia (1967-1971) formulou as possibilidades de transformar a natureza amazônica em recursos econômicos, citando com destaque os "recursos hidrológicos", representados pelo potencial hidrelétrico das águas e pela fauna aquática (Batista, 2016). No $1^{\circ}$ Plano de Desenvolvimento da Amazônia (I PDA/1972-1974) as águas dos rios amazônicos foram classificadas como "grande faixa de recursos": via natural de transporte, fonte de alimentos, mas principalmente como geradoras de energia hidrelétrica (Sudam, 1972). Na vigência do 20 Plano de Desenvolvimento da Amazônia (II PDA/1975-1979), teve início a ação efetiva na gestão das águas para construção de hidrelétricas na região, por meio das Centrais Elétricas do Norte do Brasil (Eletronorte), estatal criada em 1973 (Sudam, 1976). O II PDA inaugurou novo contexto histórico de relação com os rios amazônicos, marcado pelo represamento das águas para geração de energia, inicialmente nas bacias dos rios 
Amazonas e Tocantins/Araguaia, onde dez usinas estavam projetadas ou em operação (Batista, 2016). Segundo Fearnside (2014), entre 1975 e 2013 foram construídas 13 barragens na Amazônia Legal. ${ }^{4}$

A implantação do Programa de Mineração Grande Carajás, na vigência do 3º Plano de Desenvolvimento da Amazônia (III PDA/1980-1985), materializou a construção da usina hidrelétrica de Tucuruí (UHT) como fator de desenvolvimento e pilar energético para os complexos mínero-metalúrgicos e industriais da Amazônia (Batista, 2016; Sudam, 1982).

Nos planos de desenvolvimento da Amazônia Legal, considerada fronteira de recursos, as águas dos rios foram fundamentais na perspectiva da subsunção da água, como força motriz das operações industriais ligadas aos grandes projetos mineradores, polos industriais e cidades. As decisões tomadas superestimaram os benefícios das represas e subestimaram os impactos sociais, ambientais e culturais, assim como os custos de construção das barragens, pois há grande desigualdade entre quem paga e quem usufrui dos benefícios (Fearnside, 2015a; 2015b). As construções de barragens causam impactos sociais, ambientais, econômicos e culturais onde quer que sejam construídas. A cultura preexistente nas comunidades amazônicas relacionada à percepção e apreensão das águas de rios e de outras fontes não foi considerada, e os novos sentidos e significados das águas - em especial dos rios - foram alterados, impondo-se outros na perspectiva mercadológica. É esse processo que se problematiza neste artigo.

\section{Rios E HISTÓRIA NA AMAZÔNIA}

A apreensão e explicação da realidade pelas sociedades enfatiza o processo de elaboração de imagens, as quais antecedem as ideias e conceitos e são construídas mediante aquisição do conhecimento. As imagens são construídas historicamente, expressam a mistura de desejo e visões, de representação de sentimentos e forças da natureza em diferentes níveis de compreensão do imaginário e da natureza a partir de referenciais que lhes dão significados, criando e recriando sentidos.

O rio como água corrente se conforma em categoria do pensamento social que identifica os imaginários sobre a água na história da humanidade, no sentido proposto por Castoriadis (1999): como fluxos ou magmas de significações que historicamente passam a ter elevado grau de autonomia. Ivan Illich (1986) identificou três dimensões imaginárias da água na história da humanidade: água dos sonhos, água como bem comum e água como $\mathrm{H}_{2} \mathrm{O}$. 
As representações das águas na cultura ocidental sofreram transformações ao longo da história. A positivação cultural e econômica dos rios ocorreu na Renascença, no século XVII, quando eles se tornaram encantamento, beleza, objeto de prazer, desejo, emoção e poder, como via de tráfego de ideias, mercadorias, de gentes e de força hidráulica. Em geral, os estudos históricos informam que as sociedades humanas sempre se estabeleceram onde a água é abundante (Coy, 2013; Bruni, 1994), próximas aos rios, lagos e outras fontes de água, seja para suprir suas necessidades biológicas de consumo seja pelo lazer, pela obtenção de alimentos nas planícies de aluvião ou pela navegabilidade de suas águas, que possibilitam o transporte, a comunicação e o comércio, conformando processos históricos vivenciados nessas relações (Senra, 2014, p. 5).

Os rios tornaram-se, então, importantes elementos geradores de renda e de poder, e como tal foram assenhoreados pelos Estados nacionais nascentes. Nesses termos, as águas se conformaram também como elemento de disputa, em especial nos processos de formação dos Estados nacionais quando, além de abastecer a sociedade, se instituíram também como vias de tráfego, enunciando a possibilidade de um (hidro)negócio, justificado e formalizado pela cobrança de tributos. Febvre (2000) discute essa e outras questões ao sistematizar a história realizada em torno do rio Reno, analisando sua importância política, econômica e cultural para a França e a Alemanha, interpretando-o como instrumento de um jogo mental de desnaturalização de espaços geográficos, e sua instituição como categoria histórica, política e econômica.

Entre cenas, cenários e referências, a água como rio se configura historicamente em categoria do pensamento social, na cultura econômica, política e na história. Sua distribuição no planeta nas diferentes regiões caracterizou-se sempre pela disparidade, o que é determinado pelos diversos ecossistemas em que aflora. Essa assimetria na distribuição das águas nos continentes propiciou a emergência de distintas ofertas e demandas, tecnologias e tensões sobre seus usos entre os povos (Queiroz, 2012).

A percepção da água como um elemento abundante e aparentemente inesgotável influenciou profundamente a formação socioeconômica do Brasil, em geral, e da Amazônia, em particular, com diversas implicações na relação entre sociedade e natureza. Com efeito, a Amazônia, por suas dimensões e presença de grande quantidade de corpos d'água, tem sido qualificada superlativamente na literatura, em discursos governamentais, relatórios administrativos, planos de governo etc. Os rios da Amazônia, anunciados e enunciados sob o mito da perenidade, propiciaram a substantivação de seus usos e uma miríade de critérios nas análises interpretativas da região. 
Na história do Brasil o pensamento social e o imaginário sobre os rios sempre foram importantes para acessar, qualificar e identificar caminhos, fronteiras, lugares, modos de vida e contatos em suas representações. Eles foram as principais vias de penetração no vasto território americano e brasileiro, na sua conquista e colonização, na organização da dinâmica da vida social, econômica e política, compondo sua história e imaginário social. Além de "caminhos" pelos quais se adentrou a região, o rio Amazonas e seus tributários foram lugares estratégicos de observação e circulação de pessoas e mercadorias. A historiografia sobre a Amazônia abordou por longo tempo os rios como via de tráfego de gentes, produtos, cultura civilizatória ou como lugar de referência às populações nativas, vilas e cidades, sempre como "caminho aquático". $\mathrm{Na}$ segunda metade do século XX os rios amazônicos passaram a ser analisados e inseridos nas reflexões políticas e econômicas como recursos hídricos compondo também as agendas econômicas na região e para a região.

A água em sua múltipla aparência natural é imprescindível à vida. A manutenção de sua qualidade e abundância é o maior desafio da humanidade, atualmente. Os obstáculos para assegurar seu acesso atual e de futuras gerações são de diversas ordens, pelas condições de como a água se encontra nos ambientes, em particular a "água doce”, que representa apenas 2,5\% das águas no planeta. Dados do Ministério do Meio Ambiente (Brasil, 2005) sobre as águas doces existentes no planeta informam que $68,9 \%$ se encontram nas geleiras e neves "eternas", $29,9 \%$ são águas subterrâneas, $0,9 \%$ compõe a umidade de solos e pântanos e apenas $0,3 \%$ compõe a água doce superficial, na forma de rios e lagos. Desse percentual, 19,8\% estão no Brasil. A maior porção de água doce brasileira situa-se na Amazônia Legal, que detém 68,5\% dos recursos hídricos do país, distribuídos em $45,3 \%$ da sua superfície. Esses dados requerem reflexão atenta das ciências, inclusive da historiografia.

Durante os últimos três séculos muitos foram os percursos de aventureiros, administradores, naturalistas, políticos e cientistas realizados na bacia hidrográfica amazônica. Essas viagens, contatos e confrontos provocaram mudanças em quase todo o planeta, em especial na região do grande rio que se tornou a Amazônia. Tais mudanças alteraram o modo de entender a Terra em sua complexa diversidade de águas (oceanos, rios e lagos), continentes, biodiversidade (naturezas) e os diferentes povos (Ugarte, 2009). Os rios amazônicos se constituem, pois, em categorias múltiplas: espacial, pensamento social, econômico, político e cultural.

A importância do rio Amazonas e de seus afluentes como vias navegáveis foi informada em diversas obras do século XVIII, por Padre João Daniel, 
Francisco Xavier Ribeiro de Sampaio, Charles Marie de La Condamine, Francisco José de Lacerda e Almeida e Alexandre Rodrigues Ferreira, entre outros. No século XIX dezenas de viajantes, como o naturalista Henry Walter Bates, também percorreram o grande rio e seus tributários para conhecê-los, estudá-los em sua complexa rede de "caminhos" no Centro-Norte da América do Sul, assim como as populações de suas margens, a flora, fauna, solos e clima, entre outros aspectos. Seus registros compõem importante acervo de fontes para a elaboração historiográfica sobre os rios e as sociedades da Amazônia no período.

Os registros dos rios da Amazônia e seus usos estão presentes, também, nas narrativas de especialistas contratados nas esferas governamentais no século XIX. As missões de exploração efetuadas por Ignácio Batista de Moura (1857-1929) no rio Tocantins e por Henri Coudreau (1859-1899) pelo Tapajós, Xingu, Araguaia, Trombetas e outros produziram informações etnográficas importantes para a compreensão dos processos históricos vivenciados em suas águas.

Arruda (2006) ressalta que os rios são partícipes em diversos processos históricos, mas que a historiografia, de modo geral, pouco se ocupou de suas interpretações, em decorrência de uma tradição teórico-metodológica que não abordava os componentes do mundo natural como problema e objeto da História. Uma mudança gradual nesse cenário vem se dando com a emergência relativamente recente do campo de estudos da História Ambiental, que, ao colocar os seres humanos e seus artefatos "dentro do fluxo global da matéria, da energia e da vida" (Cabral, 2014, p. 26), tem se debruçado sobre o papel das dinâmicas fluviais em face de processos econômicos, sociais, culturais, políticos e tecnológicos.

O historiador ambiental Donald Worster (2008), ao discutir os usos dos rios para a agricultura no contexto do oeste dos Estados Unidos no século XX, salienta a importância da água e do solo para o desenvolvimento das atividades agrícolas. Para ele, diferente da terra, um termo fixo, a água é um elemento natural volátil e incerto, de natureza móvel. No entanto, essas características têm sido sistematicamente ignoradas pela agricultura industrial irrigada, nos Estados Unidos e em outros países. A contribuição que Worster traz para a historiografia é a discussão da reconfiguração da água como mercadoria especial no mundo financeiro.

Ao abordar as mudanças de sentidos e significados da água, Worster demonstra que ela deixou de significar alimento, caminho aquático/via, lugar de observação e cobrança de tributos, fator matemático nas equações "agricultura, indústria e abastecimento urbano", para se tornar elemento de avaliação e categoria analítica estritamente econômica no mercado financeiro. Nesse 
sentido, segundo Worster, a água vem se constituindo em commodity $-\mathrm{H}_{2} \mathrm{O}$, potencialmente avaliada como capital para ser investido num dia e gasto livremente, quando um fictício mercado de águas estiver em alta. Desse modo, a água tem se configurado apenas como fluxo de caixa e não mais como parte vital da natureza e da humanidade. Entrecortada por uma extensa rede de rios que armazenam um volume colossal de águas, a Amazônia tem sido o locus por excelência dessas ressignificações.

No contexto dos debates sobre as questões ambientais que têm marcado o século XXI, o diálogo entre os diferentes campos de conhecimento tem sistematizado discussões voltadas à gestão dos recursos hídricos, às representações sociais sobre os ambientes aquáticos, aos impactos antropogênicos nos ciclos da água, às crises de abastecimento de água etc. ${ }^{5}$ Em recentes produções historiográficas sobre a Amazônia na perspectiva histórico-ambiental, as águas têm sido problematizadas pela abordagem das dinâmicas socioeconômicas, políticas, culturais e ambientais realizadas às suas margens e no seu curso (Batista, 2016; Mourão, 2011; Leonardi, 1999).

Os rios da Amazônia por sua dimensão física, cultural e finita apresentam, pois, múltiplas possibilidades de investigação e reflexão multidisciplinar e transdisciplinar, configurando perspectivas novas de conhecimento para a historiografia amazônica e brasileira.

\section{Os Rios No DESENVOLVIMENTO DA AMAZÔNIA}

A promoção do desenvolvimento econômico da Amazônia por meio da exploração de seus recursos naturais constituiu uma das premissas centrais do planejamento governamental contemporâneo na região, com importantes implicações sobre a gestão e uso de suas águas (Batista, 2016). É importante salientar que os diversos modos de apropriação e uso das águas amazônicas refletiram conjunturas históricas e institucionais distintas, não tendo se desenvolvido de forma ininterrupta e/ou linear.

Os usos dos rios amazônicos navegáveis, seus afluentes e cursos d'água perenes se orientaram, desde a conquista europeia, pela tradicional jurisdição ibérica baseada no direito romano, com as adequações efetivadas no mundo medieval e moderno. As águas pertenciam aos direitos reais e sua utilização dependia de concessão régia, assegurando seu domínio e propriedade, isto é, o monopólio e controle do "grande rio" e dos demais cursos d'água para a Coroa. Esta, desde o início da colonização, instituiu a cobrança de taxas pelo 
uso das suas águas para navegação, cobradas sobre as cargas das canoas, fossem elas de nativos apresados e/ou das especiarias.

Grande parte da história regional se realizou e foi marcada pela navegação de seus rios, por questões geopolíticas relacionadas à necessidade de ocupação e pelo imperativo econômico de identificação e exploração dos produtos de suas águas. A relevância desses produtos na configuração do sistema produtivo organizado no interior da ordem colonial é demonstrada pelo Repertório Documental para Memória da Pesca Amazônica (Furtado et al., 2002), compilação de fontes do século XVIII, revelando a captura e circulação de peixes frescos e salgados, crustáceos e tartarugas abastecendo vilas, cidades e a Tesouraria Geral do Comércio.

A atenção que a Coroa portuguesa dedicou à navegação pelo rio Madeira como rota entre Belém e Mato Grosso ao longo do século XVIII visava à consolidação da presença lusa na região do Madeira-Guaporé-Mamoré, área disputada pela Espanha (Costa, 2002). Relatórios produzidos nas viagens oficiais de exploração de rios na Amazônia no século XIX para estudos dos aspectos sociais, climáticos e geológicos orientavam o estabelecimento de rotas de navegação. ${ }^{6}$

Nas negociações sobre a incorporação do Acre ao Brasil, formalizada pelo Tratado de Petrópolis, o rio Purus, um dos mais extensos da bacia amazônica, foi percorrido por Euclides da Cunha, no ano de 1905. A Comissão Mista Brasileiro-Peruana de Reconhecimento do Alto Purus, chefiada por ele, contribuiu com a fixação da fronteira brasileira com o Peru e produziu um eloquente registro daquela parte da Amazônia, interpretando-a como desconhecida e abandonada pelo Estado brasileiro.

Nas esferas governamentais, a navegação fluvial foi sistematicamente apontada como um dos indutores centrais da integração e do desenvolvimento da Região Amazônica. Isso se deve ao fato de o Amazonas e seus afluentes serem típicos rios de planície, navegáveis em quase toda sua extensão (Queiroz, 2012). As ações governamentais sobre os rios amazônicos até o final do século XIX voltaram-se, portanto, de modo especial, ao (re)conhecimento de sua utilidade para navegação, comércio e demarcação de fronteiras.

A expansão da tecnologia de aproveitamento da força hidráulica para geração de energia elétrica no Brasil, a partir do início do século XX, inaugurou gradualmente um novo modo de apropriação das águas. ${ }^{7}$ A crescente industrialização, impulsionada pelas iniciativas nacional-desenvolvimentistas de Getúlio Vargas (1930-1945), ampliou significativamente a demanda por energia elétrica no país, exigindo a construção de novas e maiores barragens. Isso 
implicou uma série de investimentos públicos em hidroeletricidade na década de 1950, financiados, em grande parte, por empréstimos externos contraídos pelo Estado brasileiro (Ioris, 2010).

De acordo com dados da Agência Nacional de Energia Elétrica (Aneel, 1999), entre 1930 e 1960 a potência hidrelétrica espalhada no país passou de 615,2 MW para 3.642,0 MW. ${ }^{8}$ Com as possibilidades de exploração energética nos cursos d'água mais próximos dos grandes centros industriais se esgotando, outras bacias hidrográficas passaram a ser consideradas (Queiroz, 2012; Ioris, 2010). Concentrando mais de 50\% do potencial remanescente, a Amazônia tornou-se um espaço estratégico para a expansão da matriz energética brasileira baseada na força hidráulica de seus rios.

A percepção das águas como recursos naturais a serem transformados em mercadorias e capital passou a orientar os governos na formulação de planos, programas e projetos para a exploração econômica das águas dos rios locais, a partir de meados do século XX. O Plano de Valorização Econômica da Amazônia, previsto no Artigo 199 da Constituição Federal de 1946 e institucionalizado pela Lei 1806, de 6 de janeiro de 1953, definia entre suas atribuições o estabelecimento de uma "política de energia", envolvendo a eletrificação dos principais centros de produção e da indústria (Plano, 1954). Em legislações posteriores a esse plano, bem como nos planos de desenvolvimento subsequentes, o Estado brasileiro elaborou a operacionalização de uma nova perspectiva de subsunção das águas amazônicas como matriz energética, configurada e materializada na projeção e construção de barragens em diversos rios da região (SPVEA, 1955).

A importância da energia hidrelétrica na composição das matrizes energéticas do país a partir de 1950 se refletiu em iniciativas voltadas à identificação das "potencialidades" dos recursos naturais da região e suas condições de aproveitamento, como inventários e levantamentos técnicos previstos nos planos de desenvolvimento. Estes destacavam o potencial energético dos rios amazônicos e subsidiaram a produção de relatórios e mapas indicando os locais com a melhor relação custo-benefício para a instalação das usinas.

Tais iniciativas foram intensificadas pela emergência de uma nova política federal de desenvolvimento para a Amazônia, que exigia a ampliação sistemática do sistema gerador de energia existente no país (Batista, 2016). Conhecida como Operação Amazônia, essa iniciativa foi delineada mediante um conjunto de dispositivos legais, entre 1966 e 1967, desdobrados em medidas técnicas e administrativas que orientaram a ação estatal na região no contexto dos governos civis-militares (Sudam, 1968). 
Pelo Decreto 63.952, de 31 de dezembro de 1968, o governo federal criou o Comitê Coordenador dos Estudos Energéticos da Amazônia (Eneram), subordinado ao Ministério de Minas e Energia (MMA). Ao Comitê cabia a supervisão dos estudos de aproveitamento hidrelétrico para suprimento de sistemas elétricos já existentes ou que viessem a ser implantados em áreas prioritárias e polos de desenvolvimento criados na Amazônia pelo Governo Federal (Brasil, 1968). Em 1969 iniciaram-se as atividades. Os trabalhos, encerrados em janeiro de 1972, entre outras ações, avaliaram as corredeiras do Itaboca, no rio Tocantins, desenvolvidas sobre rochas duras, metamórficas, como de alto potencial para produção de energia hidrelétrica, fundamentando a decisão de se construir ali a usina hidrelétrica de Tucuruí, a qual foi incluída na programação do II PDA.

A partir das observações feitas nesses levantamentos técnicos, o aproveitamento hidrelétrico das águas amazônicas passou a ser gradualmente viabilizado. Com efeito, embora o potencial de produção energética das águas da Amazônia estivesse presente nas premissas do planejamento governamental desde o $1^{\circ}$ Plano Quinquenal da Superintendência do Plano de Valorização Econômica da Amazônia (SPVEA, 1955), somente na segunda metade dos anos 1970 as condições econômicas para seu efetivo aproveitamento se concretizaram. ${ }^{9}$ Um dos marcos da ação governamental na gestão das águas como recurso hídrico foi a criação das Centrais Elétricas do Norte do Brasil (Eletronorte), em junho de 1973, com a finalidade de "realizar estudos, projetos, construção e operação de usinas de energia elétrica e sistemas associados de transmissão, assim como a coordenação dos programas de energia elétrica na região amazônica” (Senado Federal, 1975, p. 14).

A necessidade de gerar energia para a industrialização dos "importantes bens minerais ocorrentes na região" (Sudam, 1976, p. 17) foi fator decisivo nesse processo. De fato, de acordo com o primeiro presidente da Eletronorte, Raul Garcia Llano, ao assumir a coordenação dos programas regionais de energia elétrica, a estatal procurou avaliar todas as importantes jazidas minerais na região do rio Tocantins, "em contato íntimo" com a Companhia de Pesquisa e Recursos Minerais (CPRM), visando caracterizar os mercados potenciais de energia elétrica para a transformação desses minerais (Llano, 1975, p. 14). ${ }^{10}$

Segundo Lúcio Flávio Pinto (1977), há íntima relação entre a exploração de recursos minerais e a apropriação dos rios amazônicos para produção de energia. A construção da usina de Tucuruí (UHT) no rio Tocantins, iniciada em 1975, se viabilizou com a instalação da empresa Alumínio Brasileiro Sociedade Anônima (Albras) no município paraense de Barcarena, em 1978. 
O funcionamento desta seria impossível sem o suporte da hidrelétrica, considerando a alta demanda energética da produção de alumínio (Pinto, 1977).

Sob a gestão da Eletronorte, além da construção da UHT, o programa de energia delineado para a Amazônia no quinquênio 1975-1979 no II PDA planejou diversas ações voltadas à apropriação das águas amazônicas, a saber: projetos visando o aproveitamento hidrelétrico dos rios Jatapu, no Amazonas, Trombetas, no Pará, Cotingo, em Roraima, e Jamari, em Rondônia, e o Inventário dos Recursos Hidrelétricos das bacias dos rios Xingu, Tapajós e Madeira. Tais ações resultaram na avaliação de um potencial energético de 100 milhões de KW a ser aproveitado nos propósitos do planejamento estatal para os anos seguintes.

O resultado das iniciativas técnicas envolvendo a mensuração da capacidade energética dos rios amazônicos naquele contexto histórico é evidenciado no mapa a seguir, indicativo das perspectivas de seu uso e aproveitamento pelas ações governamentais.

Figura 1 - Mapa de aproveitamento hidrelétrico nas bacias do rio Amazonas e Tocantins/Araguaia

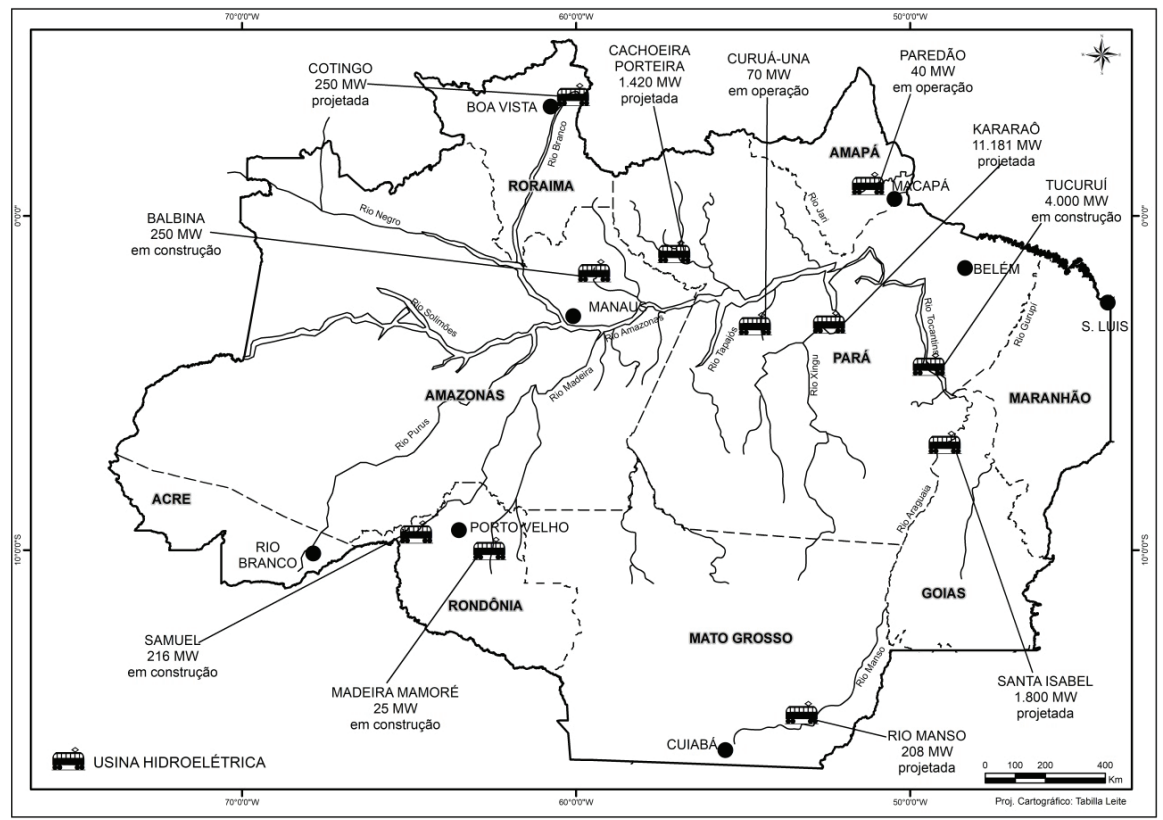

Fonte: Junk; Mello, 1987, p. 368. Adaptado por Tabilla Leite. 
A localização das usinas projetadas revela a estreita associação entre projetos energéticos e o desenvolvimento do setor mineral na Amazônia. A primeira usina hidrelétrica da região, Coaracy Nunes, instalada no rio Araguary, surgira em função da exploração do manganês no território amapaense (Drummond; Nascimento, 2003). Por sua vez, os estudos para criação da usina da Cachoeira Porteira, no rio Trombetas, preconizados no II PDA, deviam-se à exploração da bauxita, ali efetuada. Igualmente, a hidrelétrica do Samuel, projetada para o rio Jamari, era motivada pela exploração da cassiterita em Rondônia (Leal, 1988).

Além dos planos de desenvolvimento, documentos como o Plano Nacional de Energia Elétrica 1987-2010 preconizaram a Amazônia como o espaço por excelência de expansão da matriz elétrica do país (Brasil, 1987). E embora limitações financeiras tenham comprometido a construção na Amazônia brasileira de todas as 68 barragens listadas no Plano, a escala de crescimento hidrelétrico planejada para a região não arrefeceu (Fearnside, 2015a; 2015b).

Ao discutir a apropriação econômica dos recursos hídricos no Brasil, Ioris (2010) salienta que a abundância e disponibilidade de água são características historicamente associadas ao país e, mais especificamente, à Amazônia. A profusão das águas influenciou a utilização de rios, aquíferos, lagoas e manguezais na produção de mercadorias e na organização de suas atividades produtivas na história do país e da região. Esse processo, de certa maneira, favoreceu gradualmente a percepção da água da Amazônia como um recurso de valor econômico. A efetivação do sentido da água nessa perspectiva avançou a partir de 1950, em termos de procedimentos regulatórios e reordenamento de uso econômico, para promover o desenvolvimento econômico da região e sua integração à economia nacional e internacional, intensificando-se sob a égide dos governos civis-militares.

Nesse contexto, a atribuição de valor econômico à água se deu em face da apropriação para geração de energia, do custo de transporte e tratamento para abastecimento humano e uso na produção de bens agrícolas, pecuários e industriais para comercialização, tendo em vista a "modernização" da agropecuária, o subsídio à instalação de novas indústrias e o atendimento às demandas dos projetos de colonização oficial, como os instalados às margens da rodovia Transamazônica. Considerando a tese de que a água passara a ser identificada como recurso hídrico e reconhecida como bem econômico, ${ }^{11}$ as políticas, os planos e projetos para a Amazônia a trataram como tal. 
A configuração da água como mercadoria é explicitada por Ioris (2010) na perspectiva do conceito de "água virtual", compreendida como a demanda hídrica necessária para a produção de uma unidade de mercadoria. No entanto, conforme apontado por diversos estudos, a valoração econômica da água inserida na lógica da acumulação tem propiciado a capitalização de benefícios para poucos e a socialização dos impactos negativos para a grande maioria da população (Ioris; Costa, 2009; Ioris, 2010; Feanrside, 2015b), em especial na Amazônia.

Por certo, se para os gestores públicos as hidrelétricas têm representado os eixos das políticas de expansão da oferta de energia planejada para o atendimento das demandas de crescimento econômico do país, suas implementações têm provocado diversos impactos socioambientais, refletindo-se em deslocamento compulsório de populações ribeirinhas, alterações do ciclo hidrológico, perda ou perturbação de vastas áreas florestais e emissões significativas de gases de efeito estufa, muitas vezes superiores às emissões cumulativas de combustíveis fósseis etc. (Fearnside, 2015b). ${ }^{12}$

E tal fato não ocorre somente no Brasil. Os impactos das construções de barragens para hidrelétricas têm sido objeto de análises comparativas. Khagram (2004) analisou a participação de setores da sociedade civil de países em vários níveis de desenvolvimento como Índia e Brasil, África do Sul e Lesoto, China e Indonésia, nos processos políticos de construção de barragens. A pesquisa concluiu que a capacidade de mobilização dos movimentos sociais frente aos interesses financeiros e políticos relativos às barragens está relacionada ao grau de democratização do país em questão e às suas articulações com redes ativistas transnacionais.

As análises econômicas que orientaram a construção de hidrelétricas na Amazônia, de modo geral não levaram em consideração os seus efeitos sociais e ambientais. Isso se deve, em parte, ao fato de terem sido decididas em contextos autoritários, a exemplo da usina de Tucuruí, alcunhada pelo jornalista Lúcio Flávio Pinto de "barragem da ditadura”. É evidente que em conjunturas políticas não democráticas, os interesses políticos e financeiros envolvendo a execução de obras da dimensão das hidrelétricas tendem a ignorar ou subestimar os seus impactos e/ou superdimensionar os seus benefícios.

Fearnside $(2014 ; 2015 a)$ e outros têm documentado os custos sociais e ambientais da construção de hidrelétricas na região, em especial os que se referem ao deslocamento de populações e aos impactos sobre os ecossistemas. Segundo dados mapeados pelos movimentos sociais dos atingidos, a construção da hidrelétrica de Tucuruí "deslocou, remanejou, expropriou povos 
indígenas, 'colonos', extrativistas, pescadores, trabalhadores rurais, moradores de ilhas, vilas e cidades a jusante" estimados na fase inicial da obra em cerca de 70 mil pessoas (PNCSA, 2014, p. 2). Mais de três décadas depois, em meio a infindáveis processos judiciais, muitos desses deslocados não receberam quaisquer compensações.

As implicações das alterações ecológicas das barragens se evidenciam de diversos modos. A conversão de um sistema lótico (de água corrente) para um lêntico (de água parada) gera a perda de muitas espécies da ictiofauna (Fearnside, 2005). A destruição de florestas por seu corte ou submersão, a formação de barreira física à migração de peixes e outros organismos, mudanças dos ciclos hidrológicos e deterioração da qualidade da água, entre outros impactos, foram constatados por diversos estudos (Fearnside, 2014; 2015b; Junk; Mello, 1987).

Machado e Souza (2003, p. 126) destacam a construção de Balbina, no Amazonas, como exemplo de ineficiência energética e prejuízos socioambientais incalculáveis. A hidrelétrica não gerou energia no volume planejado e inundou uma imensa área habitada pelos indígenas Waimiri-Atroari, além de tornar trechos dos afluentes dos rios Uatumã e Abonari inabitáveis em razão dos gases oriundos da putrefação da floresta submersa.

Os impactos se estenderam às relações socioculturais das populações ribeirinhas com os cursos d'água amazônicos. Estudos histórico-antropológicos evidenciam que as atividades produtivas dessas populações têm sido demarcadas pelos processos naturais como cheia e seca dos rios, revelando um saber prático em consonância com a lógica dos ambientes da natureza (Acevedo; Castro, 1998; Morán, 1990). O alagamento de extensas áreas para a construção de reservatórios, ao "afogar" vastas extensões de floresta provocando o deslocamento permanente de comunidades ribeirinhas e povos indígenas, afastou-as não apenas de seu meio de subsistência, mas de um locus de práticas culturais.

Diversos mitos existentes na cultura da região revelam o caráter simbólico da água para além de suas funções de fonte de proteína e meio de transporte. Galvão (1955) identificou seres sobrenaturais denominados genericamente de "bichos visagentos" pelas populações ribeirinhas, associados a um elemento natural, como um rio, igarapé ou trecho de mata. A crença na existência de seres protetores das referências geográficas aquáticas, incluindo os lugares de atracamento de canoas, chamados "mãe do rio" ou "mãe da lagoa", era motivo de alternância constante de locais de pesca pelos ribeirinhos, assegurando, assim, o tempo necessário à reprodução das espécies. 
A expansão capitalista sobre a natureza amazônica, preconizada nos planos de desenvolvimento, engendrou movimentos de modificação e/ou reconfiguração das relações entre sociedade e natureza na região. Esse argumento pode ser ilustrado pelas mudanças nos usos das águas amazônicas. A água, representada pela fórmula química $\mathrm{H}_{2} \mathrm{O}$, refere-se ao elemento natural, desvinculado de qualquer utilização. Por sua vez, a expressão recurso hídrico representa a água como bem econômico, passível de apropriação e uso, para a geração de energia, por exemplo.

Os rios amazônicos, fontes milenares de alimentação, mananciais de água, meios de transporte e de comunicação, demarcadores de temporalidades e habitat de seres encantados, no contexto do planejamento governamental passaram a ser projetados na perspectiva de uma rede de produção e distribuição de energia elétrica. Sua função primordial no deslocamento de pessoas e mercadorias perdeu relativa importância assim que as rodovias, símbolos do desenvolvimento à época, foram construídas.

As transferências compulsórias de populações ribeirinhas em razão do barramento do curso normal dos rios para a geração de energia afetaram profundamente suas vidas. Obrigadas a abandonar as atividades produtivas dependentes da proximidade das águas, em especial a pesca, sofreram restrições à sua mobilidade e ficaram desprovidas de meios para instrumentalizar o conhecimento que acumularam sobre os usos materiais e simbólicos da natureza (PNCSA, 2014).

A apropriação da força das águas pelas políticas energéticas do Estado brasileiro refletiu concepções de progresso e desenvolvimento, consolidadas na perspectiva dos processos de economias comerciais e industriais em contínua expansão, orientadas pelo domínio da técnica e pela lógica do sistema financeiro internacional. Esse processo, no final do século XX, reconfigurou o sentido e o significado das águas dos rios em commodities.

Economistas diversos têm desenvolvido teses sobre a commoditização, isto é, a financeirização de componentes da natureza ou ambientes em mercados futuros, ou seja: "o negociar compromissos de compra e venda de coisas que serão realizadas no futuro", cuja finalidade é ganhar dinheiro com a variação de preços, que mudam constantemente. A economista ambientalista Amyra El Khalili (2018, p. 132) define commoditização da natureza como o processo argumentativo/discursivo e administrativo que transforma bem comum em bem privado. A “água, que na linguagem jurídica é chamada de bem difuso, deixa de ser bem público para ser privatizada". A "financeirização é a ação de tornar financeiro aquilo que é eminentemente econômico". Isto é, o 
bem natural é transformado em econômico quando lhe é agregado o trabalho que o transforma em manufatura/mercadoria, e torna-se produto financeiro quando passa a significar apenas valor no mercado, sendo negociado em bolsa em operações estritamente financeiras.

A estratégia para a reconfiguração do significado econômico do "bem" ocorre por meio da conformação econômica do sentido de valor que se processa com a criação de critérios e a padronização de impostos por multinacionais e governos, para transformar uma matéria-prima em commodity, resultando, portanto, também em mudança cultural. Como commodity o bem passa a representar um valor, e assim é negociado no mercado financeiro. As commodities ambientais surgiram no bojo dos debates ecológicos e preservacionistas, na perspectiva de evitar a extinção de recursos naturais, mas como demonstra Worster (2008), elas têm sido adotadas pelo mundo financeiro como commodities convencionais.

Para a História Ambiental a apropriação dos recursos da natureza reflete o sistema de relações socioeconômicas, políticas e culturais historicamente construídas. A análise das fontes utilizadas neste artigo demonstra que as ideias norteadoras do planejamento do desenvolvimento da Amazônia reduziram a natureza às dimensões utilitaristas e financeiras. É nessa perspectiva que de fontes de alimentos e vias de circulação de gentes, produtos e ideias, os rios passam a ser mensurados quantitativamente em quilowatts e commodities.

\section{CONSIDERAÇÕES FINAIS}

Uma das questões significativas que se coloca no tempo presente em relação a uma história social das águas é a compreensão de que o cálculo econômico como lógica da gestão da água e dos rios está no lugar da racionalidade ecológica, e que o resultado pode ser o declínio da civilização atual. Worster (2008) salienta a necessidade de se cultivar os rios e a correnteza da água, pois esta não pode ser "construída", sendo limitada, em seu movimento, ao que existe no planeta. Nesse sentido, a água não pode nem deve ser reduzida à dimensão de hidronegócio, já que constitui um direito humano fundamental, do qual depende a viabilidade da vida. Dado seu caráter vital, compete à sociedade definir os limites de sua apropriação tanto por políticas energéticas como pelo mercado.

A história dos usos das águas de rios amazônicos como fontes de energia elétrica tem sido norteada por interesses políticos e financeiros do Estado brasileiro e de empresas secundarizando as necessidades sociais, humanas e 
ambientais de parcelas da sociedade regional, particularmente das populações afetadas direta e/ou indiretamente pelas barragens construídas. Mas essa também é uma história de resistências, protagonizadas por indígenas, quilombolas, intelectuais e organizações não governamentais, entre outros, cujas mobilizações em determinados contextos comprometeram a escala e o cronograma de planos de expansão hidrelétrica e deram visibilidade e ressonância ao debate das consequências de projetos hidrelétricos na Amazônia. ${ }^{13}$ Nesse processo, a dimensão sociocultural dos rios foi evidenciada. Cultivar as águas amazônicas, na perspectiva preconizada por Worster (2008), requer que seus usos considerem esse conteúdo simbólico, historicamente produzido nas relações entre as sociedades regionais e seus cursos d'água. Isso significa ultrapassar a dimensão utilitarista orientadora do planejamento energético estatal na região, regulado pela lógica do mercado financeiro. É imperativo repensarmos nossa relação com a água!

\section{DEDICATÓRIA}

Este artigo é dedicado à memória de Dilma Ferreira Silva, coordenadora regional do Movimento dos Atingidos por Barragens (MAB) em Tucuruí, Pará, assassinada em 22 de março de 2019.

\section{REFERÊNCIAS}

AB'SÁBER, Aziz. Os domínios de natureza no Brasil: potencialidades paisagísticas. São Paulo: Ateliê Editorial, 2003.

ACEVEDO, Rosa; CASTRO, Edna. Negros do Trombetas: guardiães de matas e rios. Belém: Cejup, 1998.

ANEEL (Agência Nacional de Energia Elétrica). O estado das águas no Brasil: perspectivas de gestão e informação de recursos hídricos. Brasília: MME/MMA/OMM, 1999.

ARRUDA, Gilmar. História de rios: história ambiental. Signos Históricos, v. 18, n. 20, p. 16-44, jul./dez. 2006.

BATISTA, Iane M. Ambiente e sociedade nos planos de desenvolvimento da Amazônia (1955-1985). 2016. Tese (Doutorado em História Social da Amazônia) - Faculdade de História, Universidade Federal do Pará (UFPA). Belém, 2016.

BEREZUK, André Geraldo; IORIS, Antonio A. R. Água, geopolítica e valores implícitos. In: CHÁVEZ, Eduardo S.; DI MAURO, Cláudio Antônio; MORETTI, Edvaldo 
(org.). Água, recurso hídrico: bem social transformado em mercadoria. Tupã: Anap, 2017. p. 34-52.

BRASIL. Decreto 63.952, de 31 de dezembro de 1968. Cria no Ministério das Minas e Energia o Comitê Coordenador dos Estudos Energéticos da Amazônia. Disponível em: https://www2.camara.leg.br/legin/fed/decret/1960-1969/decreto-63952-31-dezembro-1968-405481-publicacaooriginal-1-pe.html. Acesso em: 12 jun. 2018.

BRASIL. Ministério de Minas e Energia. Plano Decenal de Expansão de Energia 2020. Brasília: Eletrobrás, 2011.

BRASIL. Ministério de Minas e Energia. Plano Nacional de Energia Elétrica 1987-2010. Brasília: Eletrobrás, 1987.

BRASIL. Ministério do Meio Ambiente. Secretaria de Recursos Hídricos e Ambiente Urbano. Plano Nacional de Recursos Hídricos. Brasília, DF, 2005.

BRUNI, José Carlos. A água e a vida. Tempo social, São Paulo: USP, v. 5, n. 1-2, p. 53 65, 1994.

CABRAL, Diogo C. Na presença da floresta: Mata Atlântica e história colonial. Rio de Janeiro: Garamond, 2014.

CASTORIADIS, Cornelius. L'institution imaginaire de la société. Paris: Éditions du Seuil, 1999.

COSTA, Kelerson. Homens e natureza na Amazônia brasileira: dimensões (1616-1920). 2002. Tese (Doutorado em História) - Universidade de Brasília. Brasília, 2002.

COY, Martin. A interação rio-cidade e a revitalização urbana: experiências europeias e perspectivas para a América Latina. Confins [En ligne], n. 18, 2013. Disponível em: http://journals.openedition.org/confins/8384. Acesso em: 18 jun. 2018.

DRUMMOND, José A.; NASCIMENTO, Elimar P. (org.) Amazônia: dinamismo econômico e conservação ambiental. Rio de Janeiro: Garamond, 2003.

EL KHALILI, Amyra. Commodities ambientais em missão de paz: um novo mundo econômico para a América Latina e o Caribe. Bragança Paulista: Heresis, 2018. Disponível em: http://antesqueanaturezamorra.blogspot.com.br/2014/01/as-commodities-ambientais-e.html. Acesso em: 23 jun. 2018.

FEARNSIDE, Philip M. Análisis de los principales proyectos hidro-energéticos en la región amazónica. Lima: DAR, CLAES, Panel Internacional de Ambiente y Energía en la Amazonía, 2014.

FEARNSIDE, Philip M. Brazil's Samuel Dam: Lessons for Hydroelectric Development Policy and the Environment in Amazonia. Environmental Management, v. 35, n. 1, p. 1-19, 2005.

FEARNSIDE, Philip M. Hidrelétricas na Amazônia: impactos ambientais e sociais na tomada de decisões sobre grandes obras. Manaus: Ed. Inpa, 2015a. v. 1.

FEARNSIDE, Philip M. Hidrelétricas na Amazônia: impactos ambientais e sociais na tomada de decisões sobre grandes obras. Manaus: Ed. Inpa, 2015b. v. 2. 
FEBVRE, Lucien. O Reno: história, mitos e realidades. [1931]. Rio de Janeiro: Civilização Brasileira, 2000.

FURTADO, Lourdes G. et al. Repertório Documental para Memória da Pesca Amazônica. Belém: Museu Paraense Emílio Goeldi, 2002.

GALVÃO, Eduardo. Santos e visagens: um estudo da vida religiosa de Itá, Amazonas. São Paulo: Cia. Ed. Nacional, 1955.

ILLICH, Ivan. $\mathrm{H}_{2} \mathrm{O}$ and the Waters of Forgetfulness. London: Marion Boyars, 1986.

IORIS, Antonio A. R. Da Foz às nascentes: análise histórica e apropriação econômica dos recursos hídricos no Brasil. In: ALMEIDA, Alfredo W. B. et al. Capitalismo globalizado e recursos territoriais. Rio de Janeiro: Lamparina, 2010. p. 211-255.

IORIS, Antonio A. R.; COSTA, Maria A. M. The Challenge to Revert Unsustainable Trends: Uneven Development and Water Degradation in the Rio de Janeiro Metropolitan Area. Sustainability, MDPI, v. 1, n. 2, p. 133-160, 2009.

JUNK, Wolfgang J.; MELLO, José Alberto S. N. de. Impactos ecológicos das represas hidrelétricas na bacia amazônica brasileira. In: KOHLHEPP, Gerd; SCHRADER, Achim. Homem e natureza na Amazônia: Simpósio Internacional e Interdisciplinar, Associação Alemã de Pesquisas sobre a América Latina (ADLAF), 1987. p. 367-386.

KHAGRAM, Sanjee. Dams and Developments: Transnational Struggles for Water and Power. Ithaca, NY: Cornell University Press, 2004.

LEAL, Aluízio. Amazônia: o aspecto político da questão mineral. 1988. Dissertação (Mestrado em Planejamento do Desenvolvimento) - Núcleo de Altos Estudos Amazônicos, Universidade Federal do Pará (UFPA). Belém, 1988.

LEONARDI, Vitor. Os historiadores e os rios: natureza e ruína na Amazônia Brasileira. Brasília: Paralelo 15: Ed. UnB, 1999.

LLANO, Raul Garcia. A hidrelétrica do Tocantins e suas repercussões na industrialização dos recursos minerais do Pará. In: SENADO FEDERAL. Comissão de Assuntos Regionais. O II PND e os programas de desenvolvimento regional do Pará. Brasília, 1975. p. 14.

MACHADO, José Alberto C.; SOUZA, Rubem. Fatores determinantes da construção de hidrelétricas na Amazônia: bases para exigência de indenização. In: NÚCLEO DE ALTOS ESTUDOS AMAZÔNICOS (NAEA). Documentos básicos: Seminário Internacional Problemática do uso local e global da água da Amazônia. Belém: NAEA, 2003.

MALVEZZI, Roberto. Hidronegócio. In: CALDART, Roseli; PEREIRA, Isabel B.; FIRGOTTO, Gaudêncio (org.). Dicionário de educação do campo. Rio de Janeiro: Expressão Popular, 2012. p. 397-404.

MORÁN, Emílio. A ecologia humana das populações da Amazônia. Petrópolis: Vozes, 1990. 
MOURÃO, Leila. Do açaí ao palmito: uma história ecológica das permanências, tensões e rupturas no estuário amazônico. Belém: Açaí, 2011.

PINTO, Lúcio Flávio. O anteato da destruição. Belém: Grafisa, 1977.

PINTO, Lúcio Flávio. Tucuruí: a barragem da ditadura. Belém: Ed. do Autor, 2010.

PLANO de Valorização Econômica da Amazônia. Rio de Janeiro: Departamento de Imprensa Nacional, 1954.

PNCSA (Projeto Nova Cartografia Social Amazônia). Caderno Nova Cartografia, n. 10. Atingidos pela hidrelétrica de Tucuruí. Mapeamento Social como Instrumento de Gestão Territorial contra o Desmatamento e a Devastação: processo de capacitação de povos e comunidades tradicionais. Manaus: UEA, set. 2014.

QUEIROZ, Fábio A. de. Hidropolítica e segurança: as bacias platina e amazônica em perspectiva comparada. Brasília: Funag, 2012.

QUEIROZ, Renato da S. Caminhos que andam: os rios e a cultura brasileira. In: REBOUÇAS, Aldo C.; BRAGA, Benedito; TUNDISI, José G. (org.). Águas doces no Brasil: capital ecológico, uso e conservação. São Paulo: Escrituras, 1999. p.671-688.

SENADO FEDERAL. Comissão de Assuntos Regionais. O II PND e os programas de desenvolvimento regional do Pará. Brasília, 1975.

SENRA, João Bosco. Água para todos: Avaliação qualitativa do processo de implementação do Plano Nacional de Recursos Hídricos. 2014. Dissertação (Mestrado em Saneamento, Meio Ambiente e Recursos Hídricos) - Escola de Engenharia, Universidade Federal de Minas Gerais (UFMG). Belo Horizonte, 2014.

SILVA, José B.; BATISTA, Iane M. O 1 Plano Quinquenal de Valorização Econômica da Amazônia de 1955: educação para o desenvolvimento amazônico. HISTEDBR [on-line], Campinas, n. 66, p. 56-72, dez. 2015.

SPVEA (Superintendência do Plano de Valorização Econômica da Amazônia). $1^{\circ}$ Plano de Valorização Econômica da Amazônia (1955-1959). Belém, 1955.

SUDAM (Superintendência do Desenvolvimento da Amazônia). I Plano de Desenvolvimento da Amazônia (1972-1974). Belém: Sudam/Serviço de Documentação e Divulgação, 1972.

SUDAM (Superintendência do Desenvolvimento da Amazônia). II Plano de Desenvolvimento da Amazônia. (1975-1979). Belém: Sudam/Serviço de Documentação e Divulgação, 1976.

SUDAM (Superintendência do Desenvolvimento da Amazônia). III Plano de Desenvolvimento da Amazônia. (1980-1985). Belém: Sudam/Serviço de Documentação e Divulgação, 1982.

SUDAM (Superintendência do Desenvolvimento da Amazônia). Operação Amazônia: Legislação Básica no 2. Belém: Sudam/Serviço de Documentação e Divulgação, 1968. 
UGARTE, Auxiliomar S. Sertões de Bárbaros: o mundo natural e as sociedades indígenas na Amazônia na visão dos cronistas ibéricos (séculos XVI-XVII). Manaus: Valer, 2009.

VARGAS, Getúlio. Discurso do Rio Amazonas. In: SUDAM (Superintendência do Desenvolvimento da Amazônia). Operação Amazônia (Discursos). Belém: Sudam, 1968.

WORSTER, Donald. Pensando como um rio. In: ARRUDA, Gilmar (org.). A natureza dos rios: história, memória e territórios. Curitiba: Ed. UFPR, 2008.

\section{NOTAS}

${ }^{1}$ Por sua vez, o Plano Decenal de Expansão Energética proposto para o período 2011-2020 (BRASIL, 2011), previa 30 novas "grandes barragens", definidas segundo Fearnside como "> 30MW" no Brasil, na Região Amazônica, além de várias pequenas barragens.

${ }^{2}$ Esse plano foi instituído pela Lei 1806, de 6 de janeiro de 1953.

${ }^{3}$ Segundo José B. Silva e Iane M. Batista, a educação foi considerada a ferramenta pela qual se introduziriam novas técnicas e métodos de trabalho, visando habilitar as populações amazônicas para um modo de vida apropriado aos objetivos do projeto de valorização econômica da região, consignado no $1^{\circ}$ Plano Quinquenal (1955-1959) (SILVA; BATISTA, 2015).

${ }^{4}$ Uma no Amapá, duas no Pará, uma no Amazonas, duas no Mato Grosso, quatro em Rondônia, duas no Tocantins e uma entre Tocantins e Maranhão.

${ }^{5}$ A esse respeito, destaca-se a institucionalização do Seminário Itinerante Franco-Brasileiro, promovido desde 2008 pela Universidade Estadual de Goiás e pela Universidade de La Rochelle, com o tema "Rios e Cidades na História do Brasil", e a discussão em torno de uma "geopolítica da água" na Amazônia produzida no contexto do Núcleo de Altos Estudos Amazônicos (NAEA/UFPA).

${ }^{6}$ Exemplares nesse sentido são os relatórios produzidos pelo militar João Martins da Silva Coutinho, que a serviço do Ministério da Agricultura do Império e da Província do Amazonas realizou viagens por diversos rios como Purus, Juruá, Madeira e Japurá (COSTA, 2002).

${ }^{7}$ As primeiras hidrelétricas no país foram instaladas nas duas últimas décadas do século XIX (IORIS, 2010).

${ }^{8}$ A expansão da geração de energia elétrica no país motivou a criação das Centrais Elétricas Brasileiras (Eletrobrás), em 1961.

${ }^{9}$ A primeira usina hidrelétrica da região, a Coaracy Nunes, instalada no Amapá, somente foi concluída em meados da década de 1970, tendo sido inaugurada pelo presidente Ernesto Geisel em 13 de janeiro de 1976. Com potência estimada em 60 MW e um lago de 24 $\mathrm{km}^{2}$, suas dimensões eram ínfimas diante dos padrões de aproveitamento energético pos- 
teriores como os efetuados em Tucuruí, Balbina e, mais recentemente, Belo Monte (DRUMMOND; NASCIMENTO, 2003).

${ }^{10}$ O II PDA (1975-1979) não deixava dúvidas sobre a importância da energia hidrelétrica para a viabilidade da atividade industrial na região: "No âmbito da Amazônia Legal, a hidroeletricidade, além de fontes de energia, poderá servir de matéria-prima para uma ampla gama de indústrias eletrotérmicas e eletrolíticas, viabilizando a transformação industrial na região de uma série de bens minerais, que, de outra forma (isto é, se não houvesse ampla disponibilidade de energia elétrica) seriam exportados in natura, ou nem sequer explorados economicamente" (SUDAM, 1976, p. 50).

${ }^{11}$ A Lei 9433/97 que definiu a Política Nacional de Recursos Hídricos (PNRH) no Brasil, adotou como base e referência o princípio $\mathrm{n}^{\circ} 4$ da Conferência Internacional de Água e Meio Ambiente, realizada em Dublin, Irlanda, em 1992, que estabelecia: "A água tem valor econômico em todos os usos competitivos e deve ser reconhecida como um bem econômico" (BEREZUK; IORIS, 2017).

${ }^{12}$ Tais impactos têm sido pesquisados e analisados em vasta bibliografia, destacando-se os estudos produzidos no âmbito do Instituto Nacional de Pesquisas da Amazônia (INPA) e do Núcleo de Altos Estudos Amazônicos (NAEA). Também têm sido sistematicamente abordados pelo jornalista Lúcio Flávio Pinto em diversas publicações (PINTO, 1977; PINTO, 2010).

${ }^{13} \mathrm{~A}$ imagem histórica, de grande carga simbólica, da guerreira Kayapó Tuíra encostando seu facão na face de um diretor da Eletronorte durante o I Encontro dos Povos Indígenas do Xingu, em 1989, é emblemática desse processo.

Artigo recebido em 30 de junho de 2018.

Aprovado em 18 de março de 2019. 